\title{
"Advocates Change the World; Evaluation Can Help": A Literature Review and Key Insights from the Practice of Advocacy Evaluation
}

\author{
Juniper Glass \\ Lumiere Consulting
}

\begin{abstract}
It is only since the new millennium that assessments of policy and systems change initiatives have been given much attention in practice or in research. A comprehensive literature review of advocacy in human services non-profit organizations (NGOs) has found a "lack of systemic, rational evaluation and measurement of the effectiveness of advocacy." Similarly, in a survey of 211 NGOs that undertake advocacy, only one in four (24.6 percent) reported that this work had been evaluated. While the survey was conducted in the United States, it is likely that Canadian NGOs are in a similar situation, not because of a lack of interest or value for evaluation but, rather, because assessing systems change initiatives is challenging territory and NGOs face considerable resource and time constraints that put such evaluation low on the priority list. This article provides a review of key insights from advocacy evaluation practice and research that may help orient and inform NGOs as they decide on evaluation strategies. I will outline the state of the field of systems-and policy-change evaluation in North America as well as its benefits and challenges. Finally, a synthesis of the main steps in advocacy evaluation planning and implementation offers a broad map to NGOs seeking to enhance this practice in their own organizations.
\end{abstract}

Keywords: advocacy, advocacy evaluation, evaluation, impact, impact assessment, measurement, non-profit, policy, social change

Resumé : Ce n'est que depuis le dernier millénaire que l'on s'intéresse davantage, en pratique ou en recherche, aux initiatives visant à créer des changements dans les systèmes et les politiques. Une analyse documentaire exhaustive des activités de plaidoyer dans les organisations à but non lucratif (ONG - organisations non gouvernementales) offrant des services humanitaires montre "un manque d'évaluation et de mesure systémique en ce qui a trait à l'efficacité du plaidoyer ". De même, dans un sondage de 211 ONG ayant des activités de plaidoyer, seule une sur quatre (24,6 pourcent) ont indiqué que ce travail avait été évalué. Le sondage a été effectué aux États-Unis, mais il est probable que les ONG canadiennes se trouvent dans une situation semblable, non par manque d'intérêt ou de reconnaissance de la valeur

Corresponding author: Juniper Glass, Independent Researcher, Lumiere Consulting, Montreal, QC; email: juniperglass@gmail.com 
de l'évaluation, mais plutôt parce qu'il n'est pas facile d'évaluer des changements de nature systémique et que les ONG doivent composer avec des contraintes de temps et de ressources qui font que l'évaluation nest pas une priorité. Cet article propose des éléments clés tirés de la pratique et de la recherche de type «advocacy» qui permettront d'informer et de guider les ONG dans leur choix de stratégies d'évaluation. Je ferai état des avancées dans le champ de l'analyse des politiques et des systèmes en Amérique du Nord, de même des avantages et des défis qui y sont liés. Finalement, une synthèse des principales étapes de la planification et de la réalisation d'une évaluation de type "advocacy" pourra guider les ONG qui souhaiteraient améliorer cette pratique dans leur propre organisation.

Mots clés : advocacy, plaidoyer, évaluation des activités de plaidoyer, évaluation, impact, évaluation de l'impact, mesure, but non lucratif, politique, changement social

It is only since the new millennium that the assessment of advocacy initiatives has been given much attention in practice or in research. A comprehensive literature review on human services non-profit organizations (NGOs) has found a "lack of systemic, rational evaluation and measurement of the effectiveness of advocacy" (Almog-Bar \& Schmid, 2014, p. 15), and only one in four US NGOs surveyed reported that their advocacy work had been evaluated (Innovation Network, 2008, p. 11). This situation appears to have arisen not due to the organizations' lack of interest or value for evaluation but, rather, because systematically assessing advocacy initiatives has been challenging and often confusing territory and NGOs face resource and time constraints that put such evaluation low on the priority list. After a decade of significant development in the advocacy evaluation subfield, it is useful to take stock of conceptual and methodological advances. This article provides a critical review of the advocacy evaluation literature as well as key insights for practice that help orient and inform non-profit managers and evaluation professionals who are becoming familiar with this subfield. Ultimately, the purpose is to encourage greater evaluation practice by assisting advocacy NGOs and their evaluators to understand the main developments, opportunities, challenges, concepts, approaches, and learning in advocacy evaluation.

\section{STATE OF THE FIELD: EMERGING PRACTICE}

Unlike program evaluation, which has enjoyed many decades of practice and scholarly attention, advocacy evaluation is an emerging field. The low level of use of evaluation by NGOs-only about one quarter of US advocacy organizations have reported that they engage in it (Innovation Network, 2008)-is not surprising given that many organizations do not have written advocacy plans to begin with (Coates \& David, 2002; Mansfield, 2010), let alone systematic assessments of this aspect of their work (Almog-Bar \& Schmid, 2014; Innovation Network, 2008). One reason for the low prevalence of advocacy evaluation is 
that NGOs have limited human and financial resources to devote to it (Bagnell Stuart, 2007; Coffman, 2009; Fine, 2007; Jones, 2011). A second reason is that advocacy evaluation can be nebulous and poses multiple challenges, which are summarized later in this article. Indeed, in one survey, NGOs stated that key hurdles facing them in advocacy evaluation were a lack of knowledge about how to measure success and a lack of internal capacity (Innovation Network, 2008). Some organizations may also be reluctant to attempt to systematically assess their advocacy activities because of a belief that their work is too complex to be measured or that evaluation would limit them to unmovable outcomes (Reisman, Gienapp, \& Stachowiak, 2007). Ironically, because of the challenge of measurement, the fallback for many NGOs is to simply record outputs, such as the number of meetings with policymakers or instances of media coverage (Almog-Bar \& Schmid, 2014; Forti, 2012). How advocates perceive and interact with evaluative practices is an under-researched area. Non-profit practitioners' perspectives are rare in the literature, with some exceptions such as Lempert (2009), although their insights and experiences would improve the development of knowledge and methods in the field (Whelan, 2008). For example, a follow-up to Innovation Network's (2008) survey of advocacy organizations' use of, and views on, evaluation would likely reveal new insights to inform efforts to make evaluation more accessible to advocates.

The first attempts to articulate cohesive approaches to assessing advocacy occurred in the international development context from the mid-1990s to the early 2000s (Mansfield, 2010). For example, USAID created the Advocacy Index to assess advocacy capacity of developing country organizations (see USAID, 2013), and ActionAid created frameworks to evaluate systems change efforts in the global south (Chapman \& Wameyo, 2001). Some academics also explored advocacy evaluation during this period (for example, Coates \& David, 2002; Fox \& Brown, 2001), but with limited uptake or dialogue (Mansfield, 2010). On the part of evaluation practitioners, there has been extensive work since the mid-2000s, in North America especially, to develop models and tools for assessing advocacy initiatives. Forward-thinking American foundations have been the key drivers as they seek to understand and boost the impacts of their grantees' advocacy efforts (Gill \& Freedman, 2014; Harvard Family Research Project, 2007; Mansfield, 2010). Evaluation consulting firms working with such foundations have produced some of the most cited and practical works in the literature to date, including Alliance for Justice (2005), Guthrie, Louie, \& Foster (2005), and Reisman, Gienapp, \& Stachowiak (2007). In 2007, the American Evaluation Association launched an interest group dedicated to advocacy and policy change that now counts over 800 members. The same year, the Harvard Family Research Project, which has innovated several tools unique to advocacy evaluation, dedicated the entire issue of the Evaluation Exchange to the topic. Today there exist newsletters, trainings, and vibrant debates in the field. Although some recent international evaluation cases have been published (for example, Jackson, 2013), the literature is now dominated by North American contexts and cases. 
A review of the primary literature of the past 10 years reveals the following highlights, each of which is briefly explored in the next section:

- nearly unanimous consensus on the opportunities and challenges of advocacy evaluation

- increasingly sophisticated conceptual development in the form of models that can be used for both planning advocacy initiatives and evaluating them

- the invention of several data gathering and analysis tools and slow, but steady growth in the use of these tools beyond their originators

- a growing number of published advocacy evaluations, but a need to accelerate this trend to provide grounded knowledge for practice.

\section{Opportunities and challenges in evaluating advocacy}

The literature concurs that the foremost reason for NGOs to undertake assessment of their advocacy work is to gain knowledge to improve strategy (Almog-Bar \& Schmid, 2014; Bagnell Stuart, 2007; Beer \& Reed, 2009; Borgman-Arboleda \& Clark, 2009; Coe \& Schlangen, 2011; Coffman, 2009; Forti, 2012; Fyall \& McGuire, 2015; Guthrie, Louie, \& Foster, 2005; Innovation Network, 2009; Jackson, 2014; Mulholland, 2010). NGOs engaging in advocacy indicate that the greatest benefit of evaluation is that it assists them in refining strategies and determining the next steps in a campaign (Innovation Network, 2008). As Forti (2012, p. 2) asserts in Measuring Advocacy: Yes We Can!, "nowhere is learning more important to success than in advocacy." Evaluative processes of data collection, outcomes identification, and external environment review and reflection support advocates to make course corrections during, and extract lessons after, an initiative. Evaluation is also promoted as a way to benefit other advocates across issue areas by sharing knowledge about what works (Beer \& Reed, 2009; Coffman, 2009; Reisman, Gienapp, \& Stachowiak, 2007). The second major opportunity presented by advocacy evaluation for NGOs is to more clearly understand and demonstrate their impact (Almog-Bar \& Schmid, 2014; Coffman \& Beer, 2015; Leat, 2012; Reisman, Gienapp, \& Stachowiak, 2007). Assessing and documenting results for stakeholders-"showing their funders, donors, colleagues and constituents that they are making a difference" (Guthrie, Louie, and Foster, 2005, p. 7) -is closely related to the need for accountability (Coe \& Schlangen, 2011; Coffman, 2009; Hammer, Rooney, \& Warren, 2010; Reisman, Gienapp, \& Stachowiak, 2007). Both funding and implementing organizations have reason to "validate advocacy investments" (Coe \& Schlangen, 2011, p. 1), whether that is a financial investment or the prioritization of advocacy among an organization's multiple activities.

Just as there is concurrence in the literature about the two main purposes of advocacy evaluation, there is an overwhelming consensus that it is methodologically challenging (Almog-Bar \& Schmid, 2014; Jackson, 2014; Mansfield, 2010), and it has earned the distinction of being one of the Evaluation Exchange's "hardto-measure" activities (Weiss, 2007). Some authors point out that program and 
advocacy evaluation have much in common in their process, as they "conduct systematic and data-based inquiries ... quantitative or qualitative ... [that] aim to provide high-quality information that has significance or value for whom or what they are evaluating" (Coffman, 2007, p. 2). On the other hand, evaluators note that the wide scope of advocacy can increase the challenge of measurement compared to program evaluation: "[Advocacy] affects and involves more people and communities (breadth), and leads to more fundamental changes in the legal, economic and social structures of society (depth) than direct service work" (Bagnell Stuart, 2007, p. 11).

Certain well-known program evaluation hurdles can be even higher when evaluating advocacy, such as attribution: "Advocates operate in a power-charged, contested, and constantly shifting context; change is fundamentally relational and involves complex and often fluid chains of influence" (Coe \& Schlangen, 2011, p. 1). A multitude of external factors influence systems and change initiatives, and the myriad of players, audiences, and interactions can be difficult to track and their influence challenging to measure (Alliance for Justice, 2005; Almog-Bar \& Schmid, 2014; Bagnell Stuart, 2007; Coe \& Schlangen, 2011; Guthrie, Louie, \& Foster, 2005; Leat, 2012; Reisman, Gienapp, \& Stachowiak, 2007; Teles \& Schmitt, 2011). Against such a backdrop, it is generally impossible to attribute changes in systems, public opinion, or policies to just one organization's actions (Alliance for Justice, 2005; Bagnell Stuart, 2007; Guthrie, Louie, \& Foster, 2005; Innovation Network, 2009; Jones, 2011; Klugman, 2010; Leat, 2012; Reisman, Gienapp, \& Stachowiak, 2007; Teles \& Schmitt, 2011).

Time frames are also a highly complicating factor. Advocacy involves quick cycles of changing strategies in response to an unpredictable external environment, especially when windows of opportunity open: "It's the nature of politics that events evolve rapidly and in a nonlinear fashion, so an effort that doesn't seem to be working might suddenly bear fruit, or one that seemed to be on track can suddenly lose momentum" (Bagnell Stuart, 2007; Coates \& David, 2002; Coffman, 2007; Guthrie, Louie, \& Foster, 2005; Teles \& Schmitt, 2011, p. 39). On the other hand, policy change "often runs at the speed of molasses" (Conner Snibbe, $2006 \mathrm{p}$. 42; Innovation Network, 2009; Jones, 2011), occurring over a long time frame, and there may even be dormant periods in which advocacy is best suspended until the external context becomes favourable again (Forti, 2012; Teles \& Schmitt, 2011). Advocacy organizations, their funders, and evaluators must track progress in the short and medium term while accepting that they cannot determine when or if the ultimate goal might be realized (Alliance for Justice, 2005; Ebrahim, 2005; Forti, 2012; Guthrie, Louie, \& Foster, 2005; Kimball, 2011; Rees, 2001; Reisman, Gienapp, \& Stachowiak, 2007).

Another challenge is that some important advocacy happens outside of the public eye and, in fact, relies on keeping tactics and results secret. Transparency is often a key goal of evaluation, but revealing strategies and results could arouse opposition and prevent progress (Jones, 2011; Mansfield, 2010). Patton (2008, p. 2) describes such a case: "This was the first time I had encountered a well-documented and highly successful intervention, carefully evaluated, where those involved 
did not want the story told. That illuminates, I think, one of the central challenges of doing advocacy evaluation. The stakes can be quite high and sharing the details of success is not a given." In addition, advocacy organizations "often face players actively working to thwart their efforts" (Guthrie, Louie, \& Foster, 2005, p. 8), and some focus on holding a policy line rather than policy improvement, in which case success would mean no change (Reisman, Gienapp, \& Stachowiak, 2007). Compared to program evaluation, whose designs overwhelmingly assume and assess forward progress, advocacy evaluation requires nuanced methods that account for elements such as active opposition or the relatively unnoticed work of maintaining policy gains.

\section{CONCEPTUAL AND METHODOLOGICAL ADVANCES}

In 2002, Coates and David (2002, p. 530) made a call to action in light of these multiple challenges: "Those of us concerned with developing M\&E/IA [monitoring, evaluation and impact assessment] tools for effective and accountable advocacy need to start breaking new ground." The field has responded with rigour, especially in the last 5 to 10 years when significant methodological development has taken place. Open access appears to be valued in the field, with many high quality tools freely available to civil society organizations and evaluators, including the following:

- The Advocate's Evaluation Toolkit by Spark Policy Institute provides accessible step-by-step guidelines to building and implementing an evaluation plan. ${ }^{1}$

- The Aspen Institute's Advocacy Planning and Evaluation Program offers online tools to build an advocacy theory of change and evaluate both domestic and international campaigns (Devlin-Foltz, Fagen, Reed, Medina, \& Neiger, 2012). ${ }^{2}$

- The Center for Evaluation Innovation provides resources on the evaluation of systems change efforts as well as of policy advocacy, including several case studies. ${ }^{3}$

- The American Evaluation Association's Advocacy and Policy Change group provides articles, blogs, conferences, and peer exchange among evaluation professionals. ${ }^{4}$

- The Innovation Network provides a clearinghouse of advocacy evaluation resources at their Point K Learning Center. ${ }^{5}$

We now examine key methodological developments and findings in the field, particularly the primacy of a conceptual map, the clarification and measurement of outcome areas and respective indicators, broad frameworks that attempt to unify the above, and tools invented or adapted for advocacy evaluation. Overall, the literature indicates that the burgeoning of advocacy evaluation concepts and methods is illuminating advocacy practice itself. Evaluation has contributed to 
a greater and more refined body of knowledge about how effective policy and systems influence happens, by promoting strategic clarity, making the conditions of successful advocacy more visible, and parsing out the stages and roles in what is usually a long-term and multi-actor endeavour.

\section{Theory of change}

Many authors emphasize the use of a theory of change (TOC) to guide advocacy evaluation (Coffman, 2009; Conner Snibbe, 2006; Forti, 2012; Foster \& Louie, 2010; Gienapp \& Cohen, 2011; Guthrie, Louie, \& Foster, 2005; Innovation Network, 2009; Jones, 2011; Klugman, 2010; Mansfield, 2010; Reisman, Gienapp, \& Stachowiak, 2007; Weyrauch, 2011). Others may not use the term, but promote the importance of a conceptual map or pathway when approaching and implementing advocacy evaluation (Coates \& David, 2002; Hardy, Wertheim, Bohan, Quezada, \& Henley, 2013; Hoefer, 2011). No matter what it is called, a useful TOC will identify the long-, medium-, and short-term outcomes of an initiative, who is to be influenced and how, and be backed by a clear rationale explaining why activities are expected to lead to their respective outcomes. Some authors and practitioners are concerned that TOC would become a static product that provides little benefit to advocates because they work in fast-changing contexts and have to shift tactics frequently (Reisman, Gienapp, \& Stachowiak, 2007; Teles \& Schmitt, 2011). This criticism is important and emphasizes the need for flexibility, such as regular review and refinement of the TOC. There is a wealth of guidance in the recent literature on ways to develop a useful conceptual map for an initiative, including, but not limited to, the advocacy evaluation guides and toolkits cited in this article.

\section{Outcomes and indicators}

Another advancement in the field that directly feeds into the use of TOC is the clarification of long-range advocacy outcomes and their respective interim outcomes to use as guideposts along the way. The broad outcome categories developed by Reisman, Gienapp, \& Stachowiak (2007) and Mansfield (2010), when synthesized, adequately cover the goals of most advocacy initiatives in all their diversity, namely empowerment, widened democratic space, improved capacity of civil society organizations, Strengthened Base of Support, Shift in Social Norms, and Policy Change. Once the priority outcomes of an initiative have been identified, it is important to clarify more specific short- and medium-term changes in the target audiences that are prerequisites toward achieving the overall goal. This "drilling down" to incremental outcomes is a key to making advocacy evaluation feasible given the unreliable timeline and external factors that can unexpectedly delay or speed up policy and systems change (Borgman-Arboleda \& Clark, 2009; Coffman, 2009; Guthrie, Louie, and Foster, 2005; Innovation Network, 2009; Kimball, 2011; Mansfield, 2010; Reisman, Gienapp, \& Stachowiak, 2007). When the goal is as broad as a shift in social norms, for example, it is essential to identify probable milestones along the way. Developing intermediate outcomes and indicators of progress in advocacy was once a major challenge in the field, but, 
today, several guides offer extensive examples of medium-term outcomes and indicators to inspire evaluation planning (for example, Coffman, 2009, 2010; Coffman \& Beer, 2015; Aspen Institute, 2013). Certain broad outcomes have received less treatment in the literature than others. Relatively few intermediate outcomes and indicators have been developed to track progress toward empowerment, a strengthened base of support, or a shift in social norms, while there has been robust methodological development within democratic space, the capacity of civil society organizations, and policy change (Mansfield, 2010). For example, many authors have created models that outline steps toward legislative or policy change, against which progress can be measured (Andrews \& Edwards, 2004; Barkhorn, Huttner, \& Blau, 2013; Casey, 2011; Kimball, 2011).

The development of clear, systematic long-, mid- and short-term outcomes and indicators may appear to be a basic development, but it has been a crucial one. Given that many NGOs appear to have been undertaking their advocacy activities without as much as a written plan, it is likely that advocates' conceptual understanding and the choice of strategies has not been as strong as it could be. Instead of being driven by favourite tactics or external events, advocates that develop meaningful outcomes and indicators give themselves clear direction and a map to get there.

\section{Models for advocacy planning and evaluation}

There have been several recent attempts to put all of these elements together into conceptual frameworks intended to be used in both the planning and evaluation of advocacy initiatives. Four of the most recent frameworks are examined below, three authored by evaluation professionals and one by scholars. Barkhorn, Huttner, \& Blau's (2013, p. 61) rubric identifies nine conditions they believe are essential to the success of policy change campaigns, including "feasible [policy] solution," "strong campaign leader," and "influential support coalition." The authors recommend that organizations rate their current state or likelihood of improvement on the nine factors to inform decision making at all stages: to choose among possible strategies, plan campaigns, evaluate success, and even for funders to select grantees. The framework has been criticized for its quantitative rating system because it "converts numbers into a proxy for judgment" and may obscure, rather than illuminate, what is most important in an advocacy strategy (Gill \& Freedman, 2014, p. 53). A more important criticism is that the tool does not distinguish clearly between internal capacity elements for effective advocacy and those that rely on external stakeholders. Furthermore, while the authors acknowledge that the rubric is mainly intended for campaigns that contribute to policy adoption, it implies that all conditions must be met for success, whereas the evaluation literature reveals the diversity of contexts and pathways by which changes take place in policies and systems.

"Climbing the Mountain" is Gill and Freedman's (2014) proposed framework for the planning and evaluation of advocacy. The approach is so incomplete-with no indicators, outcomes, or audiences identified - that it cannot be described as 
a model in itself. The authors do make an important contribution, however, by identifying phases of policy advocacy (likened to the process of mountain climbing) and offering corresponding evaluation questions for each phase. The usefulness of the framework lies in adding a layer of reflection to advocacy strategy planning and assessment related to what stage an initiative is at, which can assist in creating realistic expectations and appropriate evaluation plans; however, the authors provide only scattered examples for using the model rather than a comprehensive guide.

Scholars Gen and Wright (2013) have synthesized other authors' advocacy logic models and theories of change into a composite grid that identifies inputs, activities, and short-, medium- and long-term outcomes. It is not likely that advocates will pick up the model, given the other more accessible, practitioneroriented toolkits in the literature that provide guidelines for use. The authors' significant contribution to the field, however, is their examination of the links between various advocacy activities, outcomes, and impacts. Most literature on TOCs emphasize the importance of clarifying the rationale for why each activity or interim outcome is expected to lead to a certain result, based on the evidence and accepted theories rather than just on the advocates' intuition. Gen and Wright (2013) perform some of this footwork by identifying theories from multiple disciplines that help explain why certain advocacy activities can be expected to lead to changes in key audiences. They recommend further empirical research on the connections between these variables to reinforce or refute their hypotheses and advance the development of methods to measure progress in advocacy initiatives.

Likely the most user-friendly and multi-dimensional framework comes from the Center for Evaluation Innovation, which has been active in the field for many years, developing, testing, and refining models and tools. Like all models described in this section, the Advocacy Strategy Framework is applicable to both planning and evaluating an initiative (Coffman \& Beer, 2015). Rather than a linear flow chart, the framework is organized with $\mathrm{x}$ and $\mathrm{y}$ axis representing arguably the two most important dimensions of success in advocacy: the targeted audiences and the changes in knowledge or behaviour sought for those audiences. The prominent place of audiences in this model sets it apart. Despite a common understanding that advocacy is meant to change the opinions and actions of targeted stakeholders, there is often little place for them in the logic models and TOCs presented in the literature. Not all important information can be contained in a one-page framework, and the authors make clear that "drilling down" to identify the specific audiences, activities, and outcomes is essential. To assist, they provide appendices containing more definitions of interim outcomes and example indicators related to each outcome.

Although advocacy evaluation frameworks that focus on outcomes and interim progress measures are the most common, the literature does not unanimously agree that they are the best. Teles and Schmitt (2011) suggest that the capacity and skill of advocacy organizations - for example, their ability to adjust their activities and messages quickly to changing external circumstances-should be prioritized 
over performance-based outcomes. Ebrahim (2005, p. 64) has proposed using an institutional-theory approach, for example, measuring the success of a human rights organization not on the basis of how many policies it has changed but, rather, "on its ability to garner resources from the public as a result of behaving how we expect it to-by fighting for a set of espoused rights and doing so through socially legitimated structures and processes ... even if it takes decades to achieve those rights." Most advocacy organizations, however, want to know what they are achieving to advance the causes that matter to them. An outcomes-based approach that measures incremental progress that includes flexibility for changing circumstances has been found by many advocates and evaluators to be a useful framework.

\section{Development and adaptation of tools}

Data-gathering tools used for advocacy evaluation include the repurposing of common program evaluation methods, such as case studies, interviews, and focus groups as well as less conventional methods such as media tracking. In addition, several methods have been innovated specifically for advocacy evaluation. Policymaker ratings offer a scale with which advocates can assess the level of support for an issue among policymakers (Coffman \& Reed, 2009). Bellwether methodology tracks political will through the opinions of influential people from many spheres of influence, not just politicians, helping to assess the extent to which key messages have been taken up and how high an issue is on the public agenda (Blair, 2007). The intense-period debrief involves focus groups with staff and stakeholders directly following high action periods in a campaign. Since it is difficult to collect data during an extremely busy period of a campaign - for example, to stop advocates for interviews when a policy window has just opened-the structured protocol of the debrief captures learning and perceptions that might otherwise be lost and deepens knowledge to inform the next steps in the strategy (Bagnell Stuart, 2007; Innovation Network, 2007). Systems mapping draws on stakeholder input to generate illustrations of the elements and connections in an existing system: for example, how a large institution functions currently, how it could work better to meet marginalized groups' needs, and how the system has shifted in response to an advocacy initiative (Coffman \& Reed, 2009). Contribution analysis is another notable method that, while not created for advocacy specifically, helps to address one of the key challenges in advocacy evaluation, namely attribution (Patton, 2008). As discussed earlier, attributing systems change outcomes to one initiative can be difficult because of the myriad of external factors affecting the advancement of a specific cause. Contribution analysis is an empirical method for challenging, collecting evidence about, and refining the causal linkages in a TOC to the point where a credible "performance story" can be told about an initiative's influence on a change in policies, attitudes, behaviours, or systems (Mayne, 2001).

The literature reveals that there has been some pick up of these new tools beyond their originators, and published advocacy evaluations increasingly describe how such tools have been applied and adapted. For example, Stachowiak, 
Afflerback, \& Howlett (2016) present three diverse examples of advocacy initiatives that have applied the policymaker ratings method to measure levels in political will, emphasizing how the original tool was modified to mitigate each organization's concerns and to ensure a good fit to the context. The current literature provides an adequate description of the intended purpose of specific advocacy evaluation tools; however, there is a need for further application and empirical analysis to explore the conditions under which various tools are best used and how they can be adapted to different contexts.

\section{Advocacy evaluation cases}

There has been an increase in the number of published evaluation cases in the last five years, a promising trend that should contribute to both practical applications and the refinement of concepts in advocacy assessment. The majority of recently published advocacy evaluation cases are prospective (for example, Gienapp \& Cohen, 2011; Hardy, Wertheim, Bohan, Quezada, \& Henley, 2013; Hughes, Docto, Peters, Lamb, \& Brindis, 2013). Cases often produce insights about effective advocacy practice and, promisingly for the advocacy evaluation field, demonstrate how many of the well-documented challenges in evaluation can be addressed practically. For example, Hughes, Docto, Peters, Lamb, \& Brindis' (2013) study of an initiative to reduce health disparities revealed that collecting data from many sources assisted in differentiating the particular contribution of the organization. Gienapp and Cohen's (2011) assessment of an education policy change effort proved that near "real-time" analysis and reporting was possible through formal and informal communications between evaluators and advocates. Beer and Reed's (2009) excellent case study demonstrates how evaluation planning has reinforced strategy and built advocacy skills among a group of organizations working to increase access to health care.

Summative or retrospective evaluations are more rare, but still present, in the literature (for example, Montague \& Lamers-Bellio, 2012; Patton, 2008; Wallack, Lee, \& Winett, 2003). Given the long-range goals of most advocacy initiatives, retrospective assessments can be useful to examine strategic points in a campaign, consolidate results, and share lessons learned. Patton (2008), for example, describes a case study conducted after a brief, but intensive, "last push" initiative by a coalition of organizations that resulted in the intended policy change. A longterm example is the 25-year review of tobacco control advocacy by the Canadian Cancer Society that produced evidence of impact using the methodology of "key event stories" and contribution analysis (Montague \& Lamers-Bellio, 2012).

Measuring advocacy capacity is the primary focus of some cases. For example, Strong and Kim (2012) evaluated changes in the competencies of 12 coalitions by collecting data two years apart. In addition to informing coalition funders that their capacity-building investments were well placed, the study also produced useful findings for advocates, such as the finding that skills in building coalitions appeared to be prerequisites for other advocacy capacities (Strong \& Kim, 2012). Given the diversity of advocacy practices and contexts, the increase in published 
advocacy evaluation cases is a trend that promises to ground, challenge, and reinforce conceptual development in the field to date.

\section{INSIGHTS FOR PRACTICE}

Building especially on the learning from recent advocacy evaluation cases, this section presents key insights for practice. This guidance was selected based upon a high degree of consensus in the literature, with four or more authors concurring, and for relevance to NGOs engaged in advocacy as well as evaluation professionals just becoming familiar with the subfield of advocacy evaluation.

\section{Build trust between evaluators and advocates}

Due to the sensitive nature of information about advocacy strategies, evaluators must develop trusting relationships with advocates (Devlin-Foltz, Fagen, Reed, Medina, \& Neiger, 2012). The literature on grassroots advocacy especially emphasizes the need for evaluators to respect the culture of the organization or movement they are assessing (Foster \& Louie, 2010; Klugman, 2010). Understanding the organization's core values is important to incorporate them, such that "the evaluation process itself can promote social justice values" (Klugman, 2010 , p. 2). As one advocacy practitioner has pointed out, initiatives "must invest a lot of up front time in immersing evaluators in the campaign so that evaluators can understand the nuances" of these core values, as well as the focal issue, other players in the field, and the organization's positioning and planned strategies (Lempert, 2009, p. 2). Coe and Schlangen (2011, p. 3) caution that the advent of complicated measurement tools, advocacy evaluation "experts," and discourse about complex methodological nuances could alienate practitioners; instead, "the drive to develop advocacy evaluation as a professional discipline must make evaluation more accessible rather than reinforce divisions between evaluators and advocates.”

\section{Plan for changes to the plan}

Advocacy evaluation plans and methods need to be flexible enough to be adapted as strategies shift (Alliance for Justice, 2005; Coates \& David, 2002; Coffman, 2007; Gienapp \& Cohen, 2011; Guthrie, Louie, \& Foster, 2005; Hughes, Docto, Peters, Lamb, \& Brindis, 2013; Kreger, Brindis, Manuel, \& Sassoubre 2007; Lempert, 2009; Reisman, Gienapp, \& Stachowiak, 2007). Just as policy and social change processes are dynamic and unpredictable, so evaluation processes must be nimble and creative. Practically, this can mean reassessing if planned indicators and interim outcomes are still the right ones or adding a new area of inquiry or target audience to the evaluation. Some evaluators plan ahead for change by setting aside part of their time for "rapid response research" to gather data and inform advocates of their responses to strategy questions as they emerge (Coffman, 2007). 


\section{Weave strategy development and evaluation planning together}

Many authors recommend that advocacy organizations apply evaluation thinking while strategy is being developed (Coffman, 2009, 2010; Devlin-Foltz, Fagen, Reed, Medina, \& Neiger, 2012; Guthrie, Louie, \& Foster, 2005; Jackson, 2014). As demonstrated in the earlier examination of frameworks intended for use in both advocacy planning and evaluation, the two go logically together because they involve clarification of the same basic elements: the change that is sought, the key audiences that hold power to impact change, "the levers by which one can influence their behaviour, and the means of pushing on those levers" (Taplin, Clark, Collins, \& Colby, 2013, p. 12). Once an advocacy strategy is in course, there can continue to be frequent feedback loops between data collection, analysis, and strategic reflection and decision making. While it is important to be realistic about the time needed to collect quality data (Foster \& Louie, 2010), advocacy evaluation case studies are demonstrating practical ways that evaluation feedback can be delivered as close to "real time" as possible (Gienapp \& Cohen, 2011; Hughes, Docto, Peters, Lamb, \& Brindis, 2013). In addition to being methodologically sound, approaches that emphasize the mutually reinforcing nature of advocacy strategy and evaluation make the latter more meaningful for advocates, who "generally feel that the worth of an evaluation is directly proportional to its ability to inform and strengthen their ongoing practice" (Borgman-Arboleda \& Clark, 2009, p. 7).

\section{Make it a group affair}

Several advocacy evaluation cases have found that a major benefit of evaluative processes has been to facilitate increased agreement and ownership of the advocacy strategy among stakeholders, be it an internal team or a coalition (Beer \& Reed, 2009; Gienapp \& Cohen, 2011; Hardy, Wertheim, Bohan, Quezada, \& Henley, 2013). For example, developing a TOC through a participatory process helps develop common understanding about what an initiative intends to accomplish, why, and how (Anderson, 2005; Innovation Network, 2009; Klugman, 2010; Reisman, Gienapp, \& Stachowiak, 2007). Establishing a workgroup that meets frequently to review data and apply learning (Innovation Network, 2009) and collectively reassess the TOC at longer intervals (Gienapp \& Cohen, 2011) are additional examples of ways to make the evaluation a collective endeavour.

\section{Get focused}

While the goals and context of advocacy initiatives are usually very broad, the success of evaluation relies on choosing priority areas to evaluate (Coates \& David, 2002; Coffman, 2009; Coffman \& Beer, 2015; Hughes, Docto, Peters, Lamb, \& Brindis, 2013). Coffman (2009, p. 11) points out that there "rarely are enough evaluation resources available to collect data on every part of the advocacy strategy ... Under these circumstances a 'less is more' approach can be wise when identifying both what to evaluate and how." Advocates are encouraged to select just a few outcomes from the TOC for measurement and analysis. The 
choice can be based on those outcomes that are most linked to the organization's unique strengths and contributions to the change effort-outcomes that are most important for proving accountability to certain stakeholders or even outcomes of which an organization is less sure-while relying on their track record in areas of strength. Coe and Schlangen (2011, p. 2) maintain that, "for 90 percent of situations, a basic and streamlined evaluation approach is likely to be the right one."

\section{Tailor tools and methods to the context}

Because of the unique context of each advocacy initiative, evaluators that "come to the table with a checklist of measures" or a one-size-fits-all approach are generally not helpful (Klugman, 2010; Lempert, 2009, p. 2) While it is useful to draw upon existing tools and lists of potential indicators, the development of methods relies to a great extent on the creativity and engaged inquiry of advocates and evaluators familiar with the context of their particular initiative. Customization is important to ensure relevance, and "it is unlikely that useful prospective tools will ever be 'off the shelf' materials" (Gienapp \& Cohen, 2011, p. 15).

\section{Recognize resource limitations and build internal capacity}

NGOs usually work within significant human and financial resource constraints (Bagnell Stuart, 2007; Coffman, 2009; Fine, 2007; Klugman, 2010). It is therefore important to avoid creating complicated evaluation processes or monitoring systems that could increase the workload of advocates (Carr \& Holley, 2013; Jackson, 2014; Klugman, 2010). At the same time, internal evaluation capacity building is often a useful objective given that so few NGOs-17 percent according to one survey-have ever had their advocacy work assessed by a professional evaluator (Innovation Network, 2008, p. 11). It can be helpful to realize that advocates already gather information inputs from various sources and conduct analysis as a matter of course in their work (Innovation Network, 2009). To increase uptake and reduce the burden on NGOs, it is useful for evaluation to build upon the data tracking systems that many organizations already have in place (Jackson, 2014). As Coe and Schlangen (2011, p. 2) eloquently state: "It is not the precision or the purity of the evaluation methodology that is important. Nor is it the application of tools alone. It is about having basic simple processes for an organization to gather intelligence and reflect on it."

\section{CONCLUSION}

Nearly 10 years ago, Reisman, Gienapp, \& Stachowiak (2007, p. 10) noted that "evaluation in this field has been viewed as a new and intimidating prospect, though it does not have to be." Today, NGOs and evaluators have access to an abundance of tools and guidance to encourage and equip them to undertake advocacy evaluation. There have been several key methodological developments in the field over the past 10 years: near-consensus on the primacy of a conceptual map, the clarification of broad outcomes areas and the measurement of respective 
interim outcomes areas, the invention and adaptation of tools specifically for advocacy evaluation, and the creation of broad frameworks that synthesize the above elements to assist practitioners with both advocacy planning and evaluation. Furthermore, the methods and guidance offered in the literature are generally quite grounded in the realities of advocacy, characterized by long-range goals, uneven pace, complex external environment, and shifting, responsive tactics.

The literature also indicates that as advocacy evaluation concepts and methods are evolving, they are shining new light on advocacy strategy and practice. Evaluation has contributed to a greater and more refined body of knowledge about how effective policy and systems influence happens, by promoting strategic clarity and making the components and conditions of successful advocacy more visible. As evaluation continues to be designed to take into account the needs, aspirations, and constraints of advocacy organizations, it will prove its worth as an important way to weave systematic learning into advocacy practice. No longer a "new and intimidating prospect," it is likely that advocacy evaluation will become increasingly taken up by NGOs.

\section{NOTES}

1 Tools for Social Innovators, "Advocate's Evaluation Toolkit," http://sparkpolicy. com/?toolkit=aet.

2 Aspen Institute, “Tools," http://www.aspeninstitute.org/policy-work/apep/tools.

3 Center for Evaluation Innovation, "Current Focus Areas," http://www.evaluationinnovation.org/current-focus.

4 American Evaluation Association, "Advocacy and Policy Change," http://comm.eval. org/apc/home/.

5 Point K Learning Center, “Transforming Knowledge into Change," http://www.pointk. org/resources/.

\section{REFERENCES}

Alliance for Justice. (2005). Build your advocacy grant making: Advocacy evaluation tool. Washington, DC: Alliance for Justice.

Almog-Bar, M., \& Schmid, H. (2014). Advocacy activities of nonprofit human service organizations: A critical review. Nonprofit and Voluntary Sector Quarterly, 43(1), 11-35. https://doi.org/10.1177/0899764013483212

Anderson, A. (2005). The community builder's approach to theory of change: A practical guide to theory and development. New York: Aspen Institute Roundtable on Community Change. Retrieved from http://www.aspeninstitute.org/sites/default/files/ content/docs/rcc/rccommbuildersapproach.pdf

Andrews, K., \& Edwards, B. (2004). Advocacy organizations in the US political process. Annual Review of Sociology, 30(1), 479-506. https://doi.org/10.1146/annurev. soc.30.012703.110542

Aspen Institute (2013). The Advocacy Progress Planner: An online tool for advocacy planning and evaluation. New York: Aspen Institute. Retrieved from http://planning. continuousprogress.org 
Bagnell Stuart, J. (2007). Necessity leads to innovative evaluation approach and practice. Evaluation Exchange: A Periodical on Emerging Strategies in Evaluation, 13(1), 10-11.

Barkhorn, I., Huttner, N., \& Blau, J. (2013). Assessing advocacy. Stanford Social Innovation Review, Spring, 58-64.

Beer, T., \& Reed, E. (2009). A model for multilevel advocacy evaluation. Foundation Review, 1(3), 149-161. https://doi.org/10.4087/FOUNDATIONREVIEW-D-09-00028.1

Blair, E. (2007). Evaluating an Issue's Position on the Policy Agenda: The bellwether methodology. Evaluation Exchange, 13(1), 29.

Borgman-Arboleda, C., \& Clark, H. (2009). Considering evaluation: Thoughts for social change and movement-building groups. ActKnowledge. Retrieved from http:// actionevaluation.org/wp-content/uploads/Considering-evaluation.pdf

Carr, M., \& Holley, M. (2013). A new approach to evaluating public policy advocacy: creating evidence of cause and effect. Presented at the 38th Annual Meeting of the Association for Education Finance and Policy, New Orleans.

Casey, J. (2011). Understanding advocacy: A primer on the policy-making role of nonprofit organizations. New York: Baruch College, City University of New York, Centre for Nonprofit Strategy.

Chapman, J., \& Wameyo, A. (2001). Monitoring and evaluating advocacy: A scoping study. ActionAid. Retrieved from http://www.eldis.org/vfile/upload/1/document/0708/ DOC21800.pdf

Coates, B., \& David, R. (2002). Learning for change: The art of assessing the impact of advocacy work. Development in Practice, 12(3-4), 530-541. https://doi. org/10.1080/0961450220149870

Coe, J., \& Schlangen, R. (2011). Looking through the right end of the telescope. Advocacy Evaluation Update: Advances in Theory, Methods, and Practice, (12), 1-2.

Coffman, J. (2007). What's different about evaluating advocacy and policy change? Evaluation Exchange, 13(1), 2-4.

Coffman, J. (2009). A user's guide to advocacy evaluation planning. Cambridge, MA: Harvard Family Research Project; Retrieved from http://www.hfrp.org/evaluation/ publications-resources/a-user-s-guide-to-advocacy-evaluation-planning

Coffman, J. (2010). Monitoring and evaluating advocacy: Companion to the advocacy toolkit. UNICEF. Retrieved from http://www.unicef.org/evaluation/files/Advocacy_ Toolkit_Companion.pdf

Coffman, J., \& Beer, T. (2015). The Advocacy Strategy Framework: A tool for articulating an advocacy theory of change. Center for Evaluation Innovation. Retrieved from http://www.evaluationinnovation.org/sites/default/files/Adocacy\%20Strategy\%20 Framework.pdf

Coffman, J., \& Reed, E. (2009). Unique methods in advocacy evaluation. Retrieved from http://www.pointk.org/resources/files/Unique_Methods_Brief.pdf

Conner Snibbe, A. (2006). Drowning in data. Stanford Social Innovation Review, 4, 38-45.

Devlin-Foltz, D., Fagen, M. C., Reed, E., Medina, R., \& Neiger, B. L. (2012). Advocacy evaluation: Challenges and emerging trends. Health Promotion Practice, 13(5), 581-586. https://doi.org/10.1177/1524839912446482 
Ebrahim, A. (2005). Accountability myopia: Losing sight of organizational learning. Nonprofit and Voluntary Sector Quarterly, 34(1), 56-87. https://doi. org/10.1177/0899764004269430

Fine, A. (2007). Using and evaluating social media for social change. Evaluation Exchange, 13(1), 24.

Forti, M. (2012). Measuring Advocacy: Yes We Can! Stanford Social Innovation Review. Retrieved from http://www.ssireview.org/blog/entry/measuring_advocacy_yes_we_can

Foster, C. C., \& Louie, J. (2010). Grassroots action and learning for social change: Evaluating community organizing. Washington, DC: Center for Evaluation Innovation.

Fox, J., \& Brown, D. (2001). Assessing the Impact of NGO Advocacy Campaigns on World Bank Projects and Policies. In J. Harris, T. Wise, K. Gallagher, \& N.R. Goodwin (Eds.), A survey of sustainable development: social and economic dimensions (pp. 352-356). Washington, DC: Island Press.

Fyall, R., \& McGuire, M. (2015). Advocating for policy change in nonprofit coalitions. Nonprofit and Voluntary Sector Quarterly, 44(6), 1274-1291. https://doi. org/10.1177/0899764014558931

Gen, S., \& Wright, A. C. (2013). Policy advocacy organizations: A framework linking theory and practice. Journal of Policy Practice, 12(3), 163-193. https://doi.org/10.108 $0 / 15588742.2013 .795477$

Gienapp, A., \& Cohen, C. (2011). Advocacy evaluation case study: The Chalkboard Project. Washington, DC: Center for Evaluation Innovation.

Gill, S., \& Freedman, T. (2014). Climbing the Mountain: An approach to planning and evaluating public-policy advocacy. Foundation Review, 6(3), 48-59. https://doi. org/10.9707/1944-5660.1211

Guthrie, K., Louie, J., \& Foster, C. C. (2005). The challenge of assessing policy and advocacy activities: Strategies for a prospective evaluation approach. San Francisco, CA: Blueprint Research and Design. Retrieved from http://www.blueprintrd.com/text/ challenge_assess.pdf

Hammer, M., Rooney, C., \& Warren, S. (2010). Addressing accountability in NGO advocacy: Practice, principles and prospects of self-regulation. Briefing Paper no. 125. One World Trust. Retrieved from https://idl-bnc.idrc.ca/dspace/bitstream/10625/49891/1/ IDL-49891.pdf

Hardy, L. J., Wertheim, P., Bohan, K., Quezada, J. C., \& Henley, E. (2013). A model for evaluating the activities of a coalition-based policy action group: The case of Hermosa Vida. Health Promotion Practice, 14(4), 514-523. https://doi.org/10.1177/1524839912461253

Harvard Family Research Project. (2007). Pioneers in the field: Four foundations on advocacy Evaluation. Evaluation Exchange, 13(1), 12-15.

Hoefer, R. (2011). Advocacy practice for social justice (2nd ed.). Chicago: Lyceum Books.

Hughes, D., Docto, L., Peters, J., Lamb, A. K., \& Brindis, C. (2013). Swimming upstream: The challenges and rewards of evaluating efforts to address inequities and reduce health disparities. Evaluation and Program Planning, 38, 1-12. https://doi.org/10.1016/j. evalprogplan.2013.01.004 
Innovation Network (2007). Data collection for advocacy evaluation: The "intense period debrief.” Innovation Network. Retrieved from http://www.pointk.org/client_docs/ File/advocacy/intense_period_debrief.pdf

Innovation Network (2008). Speaking for themselves: advocates' perspectives on evaluation. Innovation Network. Retrieved from http://www.innonet.org/client_docs/File/ advocacy/speaking_for_themselves_web_basic.pdf

Innovation Network (2009). Pathfinder: A practical guide to advocacy evaluation. Innovation Network. Retrieved from http://www.pointk.org/resources/files/pathfinder_ advocate_web.pdf

Jackson, A. (2013, August). Panel on policy and regulation of philanthropy and foundations. Presented at the Summer Institute, Philanthropy and Nonprofit Leadership, Carleton University.

Jackson, A. (2014). Evaluation of public policy advocacy: Challenges, principles and BESTAC case study. International Journal of Public Sector Management, 27(4), 272-280. https://doi.org/10.1108/IJPSM-06-2011-0079

Jones, H. (2011). A guide to monitoring and evaluating policy influence. Overseas Development Institute Background Note. Retrieved from https://www.odi.org/sites/odi.org. uk/files/odi-assets/publications-opinion-files/6453.pdf.

Kimball, K. (2011, March). The six conditions: interim outcomes to measure progress toward significant policy change. Notes from a presentation at the Meeting of Education Funders Strategy Group. Retrieved from http://www.slideshare.net/kristikimball/thesix-conditions-interim-outcomes-to-measure-progress-toward-significant-policychange

Klugman, B. (2010). Evaluating social justice advocacy: A Values based approach. Center for Evaluation Innovation. Retrieved from http://evaluationinnovation.org/sites/ default/files/Klugman\%20Brief.pdf

Kreger, M., Brindis, C., Manuel, D. M., \& Sassoubre, L. (2007). Lessons learned in systems change initiatives: benchmarks and indicators. American Journal of Community Psychology, 39(3-4), 301-320. https://doi.org/10.1007/s10464-007-9108-1

Leat, D. (2012). Letter to a novice trustee. London: Diana, Princess of Wales Memorial Fund.

Lempert, T. (2009). An advocate's perspective: Ten considerations for effective advocacy evaluation. Children Now. Retrieved from http://www.innonet.org/resources/files/ Lempert_10_Considerations.pdf

Mansfield, C. (2010). Monitoring and evaluation of advocacy campaigns: Literature review. Ecumenical Advocacy Alliance. Retrieved from http://www.e-alliance.ch/en/s/ advocacy-capacity/resources/evaluating-advocacy-activities/

Mayne, J. (2001). Addressing attribution through contribution analysis: Using performance measures sensibly. Canadian Journal of Program Evaluation, 16(1), 1-24.

Montague, S., \& Lamers-Bellio, K. (2012). Advocacy evaluation theory as a tool for strategic conversation: A 25-year review of tobacco control advocacy at the Canadian Cancer Society. Canadian Journal of Program Evaluation, 24(3), 125-138.

Mulholland, E. (2010). New ways to keep up our end of the policy conversation. Philanthropist, 23(2), 140-145. 
Patton, M.Q. (2008). Advocacy impact evaluation. Journal of Multidisciplinary Evaluation, $5(9), 1-10$.

Rees, S. (2001). Effective advocacy on limited resources. In E. Reid \& M. Montilla (Eds.), Exploring organizations and advocacy: Strategies and finances. Nonprofit advocacy and the policy process: A Seminar Series (Vol. 1, pp. 9-16). Washington, DC: Urban Institute Press. Retrieved from http://www.urban.org/UploadedPDF/org_advocacy.pdf.

Reisman, J., Gienapp, A., \& Stachowiak, S. (2007). A guide to measuring advocacy and policy. Baltimore, MD: Annie E. Casey Foundation.

Stachowiak, S., Afflerback, S., \& Howlett, M. (2016). Measuring political will: Lesons from modifying the policymakers ratings methods. Center for Evaluation Innovation. Retrieved from http://www.evaluationinnovation.org/sites/default/files/ORS\%20 PMR\%204-2016.pdf

Strong, D.A., \& Kim, J.Y. (2012). Defining, building, and measuring capacity: Findings from an advocacy evaluation. Foundation Review, 4(1), 40-53. https://doi.org/10.4087/ FOUNDATIONREVIEW-D-11-00028

Taplin, D. H., Clark, H., Collins, E., \& Colby, D. C. (2013). Theory of change technical papers: A series of papers to support development of theories of change based on practice in the field. New York: ActKnowledge. Retrieved from http://www.theoryofchange.org/wpcontent/uploads/toco_library/pdf/ToC-Tech-Papers.pdf

Teles, S., \& Schmitt, M. (2011). The elusive craft of evaluating advocacy. William and Flora Hewlett Foundation. Retrieved from http://www.hewlett.org/uploads/documents/ Elusive_Craft.pdf

USAID (2013). The art of advocacy: Practical strategies for a more effective campaign. Presented at the Webinar. Retrieved from http://usaidlearninglab.org/sites/default/ files/resource/files/ArtOfAdvocacyPresentation.pdf

Wallack, L., Lee, A., \& Winett, L. (2003). A decade of effort, a world of difference: The policy and public education program of the California Youth Violence Prevention Initiative. Woodland Hills, CA: California Wellness Foundation.

Weiss, H. (2007). From the director's desk. Evaluation Exchange: A Periodical on Emerging Strategies in Evaluation, 13(1), 1.

Weyrauch, V. (2011). Learners, practitioners and teachers: Handbook on monitoring, evaluating and managing knowledge for policy influence. Buenos Aires: Fundación CIPPEC.

Whelan, J. (2008). Advocacy evaluation: Review and opportunities. Justin Whelan. Retrieved from http://www.innonet.org/resources/node/464

\section{AUTHOR INFORMATION}

Juniper Glass is an independent researcher and principal of Lumiere Consulting. She holds a Master's degree in philanthropy and non-profit leadership. Her primary interests are social change strategy and philanthropy. 